\title{
昆虫の生産する生態相関物質の合成研究
}

\author{
桑 原 重 文* \\ 茨城大学農学部
}

\section{Synthesis of Some Insect Semiochemicals}

\author{
Shigefumi KUWAHARA* \\ Laboratory of Agricultural Chemicals, Faculty of Agriculture, Ibaraki \\ University, Ami-machi, Inashiki-gun, Ibaraki 300-0393, Japan
}

\section{はじめに}

昆虫は各種のフェロモンを用いて生物種内での情報を伝 達し合い，またアロモン，カイロモンなどのアレロケミカ ルを用いて同種以外の個体と相互作用を及ぼし合いなが ら，自然生態系の中で巧みに生存している，そのような昆 虫間の相互作用や，植物と動物間および植物と植物間の相 互作用について興味梁く解説された化学生態学一般への入 門書も出版されているので, 是非御一読をお萀めしたい1). 本稿では, 筆者らの研究室で最近行われた昆虫の生産する 生態相関物質 (semiochemicals, eco-chemicals) の合成研究 のうち, 2 種のフェロモンと 1 種のエリシターの合成を，そ れらにまつわる生態学的背景とともに紹介させていただき たい.

\section{ミナミアオカメムシの生産する性フェロモンの合成}

ミナミアオカメムシ (Nezara viridula) は世界中の熱帯か ら温帯地域に広く分布し，広範な農作物を食害する害虫と して知られている。このカメムシの雄が放出する性フェロ モンについては, Baker らおよびAldrich らにより単離·構 造決定がなされ ${ }^{2,3)}$, Fig. 1 に示すような(Z)- $\alpha$-bisabolene の 2，3-位が側鎖に対して cis および transにエポキシ化され た 1 および 2 がフェロモン活性の主要部分をなすことが明 らかにされた. Table 1 に示したように，世界各地に生息す るミナミアオカメムシは，その生息地域によって 1 との 比率が大きく異なっており，日本のミナミアオカメムシは 1 と 2 の比率が約 1：1 であるが, アメリカ大陸のものでは trans-体の 2 が主成分となっている. 同じ種でありながら このように生息域によって成分比率が異なることに対し

* 現：東北大学大学院農学研究科 (981-8555 仙台市青葉区 堤通雨宮町 1-1)
て, Aldrich は以下のようなストーリーを展開している ${ }^{3,4)}$. 即ち, アメリカ大陸にもともと生息していた近縁の Acrosternum 属のアオカメムシも 1 と 2 の混合物をフェロモン としており (Table 1, 下段)，その比率は cis-体である 1 が 圧倒的に優勢である。またアメリカ大陸には，このAcrosternum 属のカメムシを寄主とし，その放出する cis-体に富 むフェロモンを手がかりとして生息場所を探索しているヤ ドリバエ (Trichopoda pennipes) が住んでいる (Fig.2). 東南アジアを原産とし，約 200 年前に新大陸に侵入したミ ナミアオカメムシは元々 1 と 2 を日本のカメムシと同様, 約 1：1の比率で持っていたが，cis-体により強く誘引され ると考えられる T. pennipes の寄生を逃れるために, 少しず つフェロモンの成分比率を trans-体に富むものに変えつ つあるというストーリーである。このように各地域のミナ ミアオカメムシが 1 と 2 を様々な比率で持っているため, その比率を分析する際の標品の提供が必要となり, 以下に 示す合成研究に着手した.

1 および 2 の従来の合成法はいずれも光学活性原料 $[(S)$-limonene または $(S)$-perillyl alcohol] から誘導する方 法を採用しているが（紙面の都合上，割愛させていただ ()$^{2,5-7)}$, 立体異性体の分離や反応の立体選択性という点 で改良の余地があると考えた．筆者らの合成を Fig. 3 に示 したが, 以下述べるように, D-pantolactone を不斉修飾子と して用いる不斉 Diels-Alder 反応により大量かつ容易に得 られる光学活性カルボン酸 $\mathbf{3}^{8}$ から 4 工程でまず 1 を合成 し，そのエポキシ環の立体化学を 3 工程で反転させること により 2 に変換するという計画である.まず, 3 をブロモラ クトン化により 4 と $\mathbf{5}$ の混合物とし $(\mathbf{4}: \mathbf{5}=1: 1.3), \alpha-$ フェニルチオカルバニオン誘導体 $6^{9)}$ と反応させると, ラク トン環が開くと同時にエポキシ環を巻いたエポキシケトン のエピマー混合物 $\mathbf{7}$ が得られた。この混合物にメチルリチ 
<smiles>CC(C)=CC/C=C(/C)C1CC[C@@]2(C)OC2C1</smiles>

1

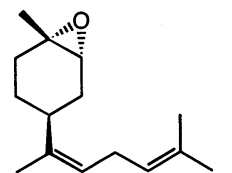

2
Fig. 1 Sex pheromone components of the southern green stink bug, $N$. viridula.

Table 1 Cis/trans ratios of geographically isolated populations of $N$. viridula.

\begin{tabular}{lc}
\hline \multicolumn{1}{c}{ Habitat } & cis/trans ratio \\
\hline Kyushu, JPN & $51: 49$ \\
Mississippi & $25: 75$ \\
Hawaii & $24: 76$ \\
California & $18: 82$ \\
Southern Brazil & $0: 100$ \\
Southern France & $42: 58$ \\
\hline Acrosternum hilare & $95: 5$ \\
A. margintum & $93: 7$ \\
\hline
\end{tabular}

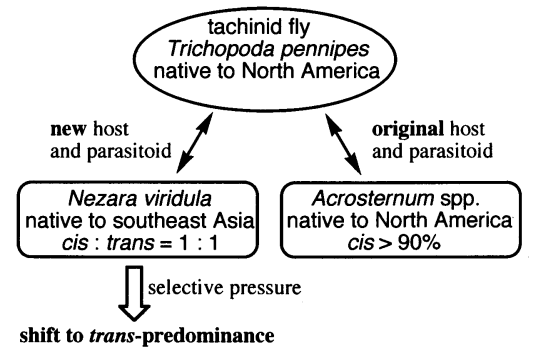

Fig. 2 Shift to trans-predominance in the pheromone blend of $N$. viridula.

ウムを作用させるとフェニルチオ基の付け根の不斉中心に よる不斉誘導が起こり, 水酸基とフェニルチオ基とが threo の関係にある 8 および 9 を立体選択的に与えた（threo： erythro=6:1).8 および9はシリカゲルカラムにより容易 に対応する erythro-体と分離可能であった. 最後に, 8 と 9 の混合物を立体特異的に anti-脱離させることにより ${ }^{10)}$, cis-エポキシ体 1 を得た。次に，1のエポキシ環を酢酸ア二 オンで開環して10 と 11 の混合物とした後 $(\mathbf{1 0}: \mathbf{1 1 = 7}$ ： 1)，生成した 3 級および 2 級の水酸基をメシラートに変換 後, 塩基性条件下メ夕ノリシスすることにより 2 へと変換 することができた. 工程数, 立体選択性の点で従来法の改 良ができたものと考えている11,12).

\section{シロイチモジョトウの唾液成分である ボリシチンの合成}

ボリシチン (volicitin) 12 は 1997 年 USDA の Tumlinson らによりシロイチモジョトウ (Spodoptera exigua) の唾夜
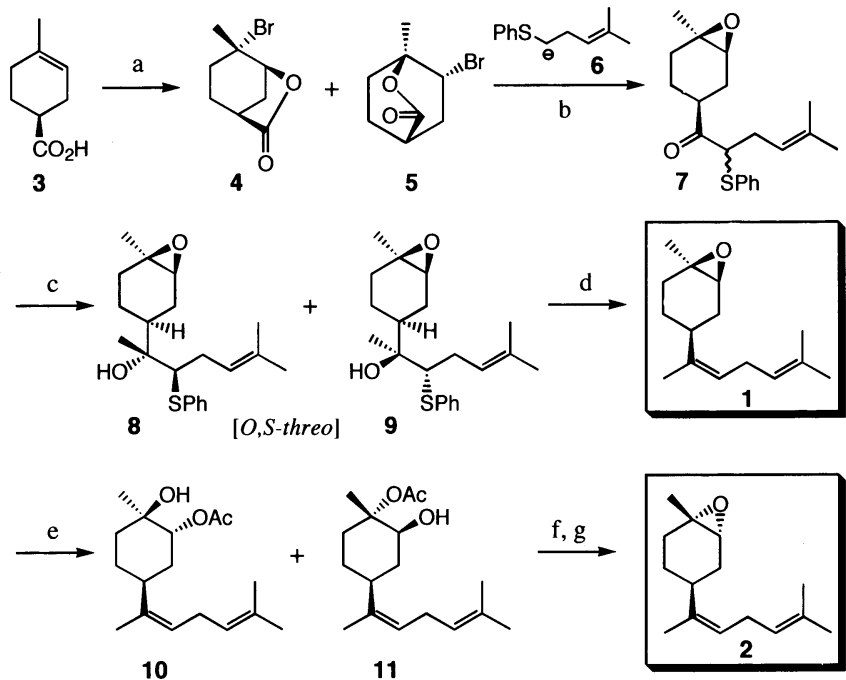

Fig. 3 Synthesis of the sex pheromone components of $N$. viridula.

Reagents: a) NBS, $\mathrm{Na}_{2} \mathrm{CO}_{3}$, DMF (86\%); b) THF (81\%); c) MeLi, THF (55\%); d) $\mathrm{P}_{2} \mathrm{I}_{4}, \mathrm{Et}_{3} \mathrm{~N}, \mathrm{CH}_{2} \mathrm{Cl}_{2}$ (49\%); e) $(n-\mathrm{Bu})_{4}$ $\mathrm{NOAc}, \mathrm{AcOH}(94 \%)$; f) $\mathrm{MsCl}, 2$,6-lutidine; g) $\mathrm{K}_{2} \mathrm{CO}_{3}, \mathrm{MeOH}$ (68\%, 2 steps).

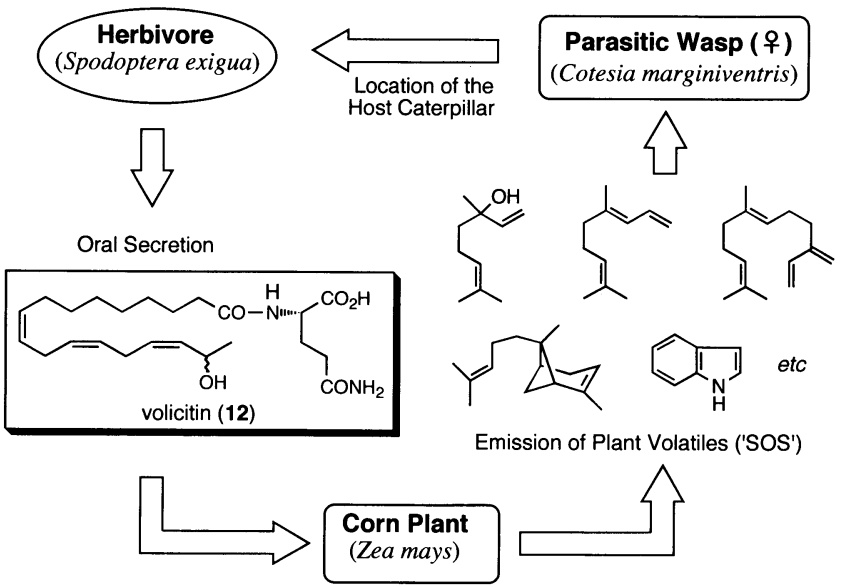

Fig. 4 Tritrophic interaction between corn plant, herbivore, and parasitic wasp.

中に見いだされた 17-ヒドロキシリノレン酸とL-グルタミ ンとのアミドである ${ }^{13)}$. Fig. 4 に示したよjに, トウモロコ シがこのヨトウムシに食害されると，唾液中に含まれる 12 を感知し，数種のテルペンとインドールとを新規に生合成 して大気中に発散する。すると，ヨトウムシの天敵である コマユバチ (Cotesia marginiventris) の雌がその臭いに誘引 されて，寄主であるヨトウムシの所在を突き止産卵する ことにより，結果的にトウモロコシはヨトウムシによる食 害の拡大をくい止めることができるという，3つの栄養段 階にまたがる大変興味深い生態が明らかにされている. 従ってボリシチン 12 は, トウモロコシにコマユバチを誘引 


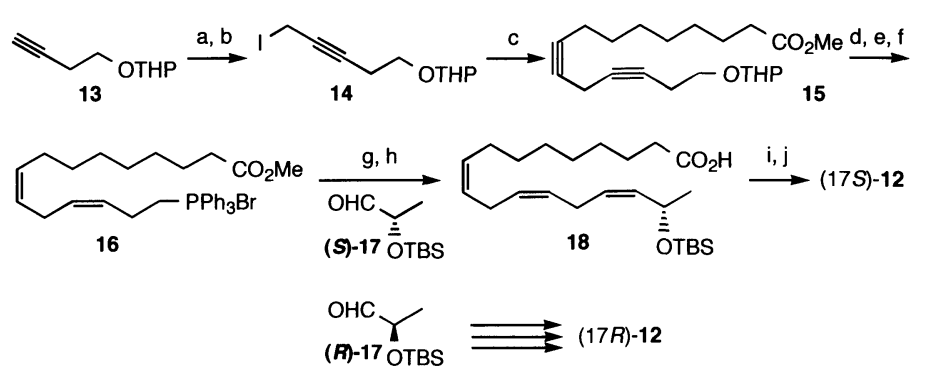

Fig. 5 Synthesis of stereoisomers of volicitin.

Reagents: a) EtMgBr, $\left(\mathrm{CH}_{2} \mathrm{O}\right) \mathrm{n}$, THF (81\%); b) $\mathrm{I}_{2}, \mathrm{Ph}_{3} \mathrm{P}$, imidazole, THF (86\%); c) methyl 9-decynoate, CuI, (n-Bu) ${ }_{4} \mathrm{NI}, \mathrm{Na}_{2} \mathrm{CO}_{3}$, DMF (82\%); d) $\mathrm{H}_{2}$, Lindlar cat., EtOH (75\%); e) $\mathrm{Br}_{3} \mathrm{C}_{6} \mathrm{H}_{3} \mathrm{OP}(\mathrm{Ph})_{3} \mathrm{Br}, \mathrm{CH}_{2} \mathrm{Cl}_{2}$ (97\%); f) $\mathrm{Ph}_{3} \mathrm{P}, \mathrm{CH}_{3} \mathrm{CN}$ (77\%); g) $\mathrm{KN}(\mathrm{TMS})_{2}$, (S)-5, THF-HMPA (52\%); i) $t$ $\mathrm{BuCOCl}, \mathrm{Et}_{3} \mathrm{~N}$, then L-Gln, $\mathrm{H}_{2} \mathrm{O}$-dioxane (86\%); j) aq. $\mathrm{CH}_{3}$ CN, THF (61\%).

する揮発性物質を生合成・発散させるエリシターとして働 いていることになる.この話題については, 近年の Nature, Science 誌などで盛んに報告されており, 近年の化学生態学 における注目すべき話題の 1 つである ${ }^{14-16)}$. 将来的にはレ セプターとの相互作用や，同様な作用を持つジャスモン酸 との関係などに研究が発展していくものと考えられるが, 17 位の水酸基の絶对立体配置を決定しておく必要性から, 両ジアステレオマーの合成を行った (Fig. 5). 13 を 2 工程 で14に変換し，これと9-デシン酸メチルとをカップリン グして 15 とした. 15 の 2つの二重結合を部分還元し, THP エーテルの臭素化 ${ }^{17)}$ を経てホスホニウム塩 16 とした. 16 を $(S)$-乳酸から導いたアルデヒド $(S)-17$ Wittig 反応 させ, エステルの加水分解により 18 とし, L-グル夕ミンと の混合酸無水物法によるアミド化により $(17 S)-12$ を得 た.また， $(R)$-乳酸から導いた $(R)-17$ を用いることによ $\eta,(17 R)-12$ を得た. 今後, 両ジアステレオマーの生物活 性試験により 17 位の絶対立体配置を決定する予定である [最近 $(17 S)$-および(17R)-12の合成が報告されたが ${ }^{18)}, 17$ 位の立体化学については述べられていない].

\section{カメムシの一種 (Tynacantha marginata) の 推定性フェロモンの合成}

USDA の Aldrich はブラジリア郊外で捕獲した雄のカ メムシ (Tynacantha marginata) のフェロモン腺の主成分 を単離し, 蚛系昆虫研究所 (現 UC, Davis) の Leal らのよ る構造解析の結果, その物質が 19 のような新規な炭素骨格 を有するセスキテルペンであることが提案された(Fig. 6). Leal らは19がフェロモン腺の主成分であることから性 フェロモンである可能性が高いと考えている．合成による 構造の確認とサンプル供給の依頼を受けた筆者らは, 19 の 構造が新規なセスキテルペン骨格であること,また 19 の光 学的な物性が測定されていないことを考慮して,まず 19 の ラセミ体を合成して構造を確認し, 次に両鏡像体を合成し て生物活性試験を実施し, 絶対立体配置を決定しようと考 之, 以下の研究に着手した.

まず 20 を $\alpha$-メチレンアルデヒド 21 に変換し ${ }^{19)}$, 酸性メ タノールでの処理とヨウ素化により側鎖部分に相当する 22 を得た. 次に, シクロペンテノン誘導体 23 を 22 でアル
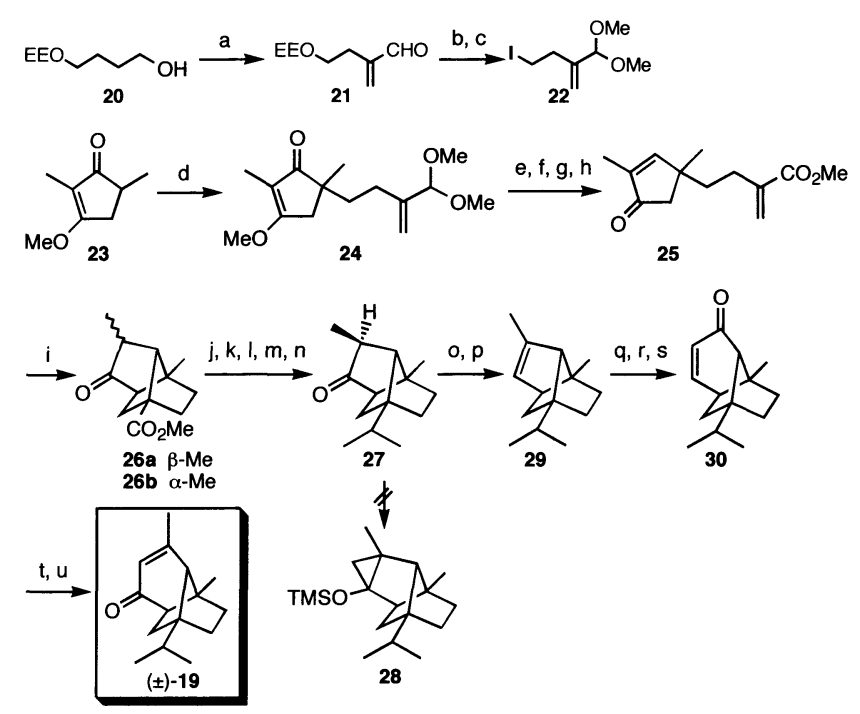

Fig. 6 Synthesis of the racemate of the putative sex pheromone of $T$. marginata.

Reagents: a) DMSO, $(\mathrm{COCl})_{2}, \mathrm{Et}_{3} \mathrm{~N}, \mathrm{CH}_{2} \mathrm{Cl}_{2}$, then $\mathrm{CH}_{2}=$ $\mathrm{NMe}_{2} \mathrm{I}(64 \%)$; b) Amberlyst 15E, MeOH (56\%); $\mathrm{I}_{2}, \mathrm{Ph}_{3} \mathrm{P}$, imidazole, THF (40\%); d) LDA, $\mathrm{ZnCl}_{2}, 20$, THF-HMPA (78\%); e) DIBAL, toluene, then $\mathrm{SiO}_{2}(68 \%)$; f) PPTS, $\mathrm{H}_{2}$ O-THF; g) $\mathrm{NaClO}_{2}, \mathrm{NaH}_{2} \mathrm{PO}_{4}, 2$-methyl-2-butene, $t$-BuOH $-\mathrm{H}_{2} \mathrm{O}$; h) $\mathrm{Me}_{3} \mathrm{OBF}_{4}$, (i-Pr) ${ }_{2} \mathrm{NEt}, \mathrm{CH}_{2} \mathrm{Cl}_{2}$ (75\%, 3 steps); i) TMSI, (TMS) $)_{2} \mathrm{NH}, 1,2$-dichloroethane (74\%); j) $\mathrm{HO}\left(\mathrm{CH}_{2}\right)_{2}$ $\mathrm{OH}$, TsOH, (MeO) ${ }_{3} \mathrm{CH}$, benzene (76\%); k) $\mathrm{MeLi} \mathrm{CeCl}_{3}$, THF (87\%); 1) $\mathrm{MeO}_{2} \mathrm{CNSO}_{2} \mathrm{NEt}_{3}$, benzene (83\%); m) $\mathrm{H}_{2}$, Pd-C, EtOH; n) PPTS, $\mathrm{H}_{2} \mathrm{O}$-acetone (87\%, 2 steps); o) $\mathrm{Tf}_{2} \mathrm{O}$, (i-Pr) $\left.)_{2} \mathrm{NEt}, \mathrm{CH}_{2} \mathrm{Cl}_{2} ; \mathrm{p}\right) \mathrm{HCO}_{2} \mathrm{H}, \mathrm{Pd}(\mathrm{OAc})_{2}\left(\mathrm{PPh}_{3}\right),(\mathrm{n}-\mathrm{Bu})_{3} \mathrm{~N}$, DMF (73\%, 2 steps); q) $\left.\mathrm{OsO}_{4}, \mathrm{Py} ; \mathrm{r}\right) \mathrm{NaIO}_{4}$, ether- $\mathrm{H}_{2} \mathrm{O}(80 \%$, 2 steps); s) $\mathrm{K}_{2} \mathrm{CO}_{3}, t$-BuOH (90\%); t) MeLi, ether; u) PCC, $\mathrm{CH}_{2} \mathrm{Cl}_{2}$ (62\%, 2 steps).

キル化して 24 とし， DIBALによりケトンを還元すると同 時にシリカゲル処理してエノールエーテルの加水分解およ び脱水を行い, 次にアセタールの脱保護, 酸化, エステル 化により 25 を得た. 25 を分子内ダブルマイケル反応の条 件に付したところ ${ }^{20)}$ ，26a と 26b が 4:1の比率で得られ た. 主生成物の 26a を精製後, メチルエステル部分をイソ プロピル基に変換して 27 を得た。当初は 27 TMS工 ノールエーテル化, シクロプロパン化により 28 とし, その 酸化的環拡大により (土)-19に導く計画だったが，27の TMS エノールエーテル体から 28 ヘシクロプロパン化が 


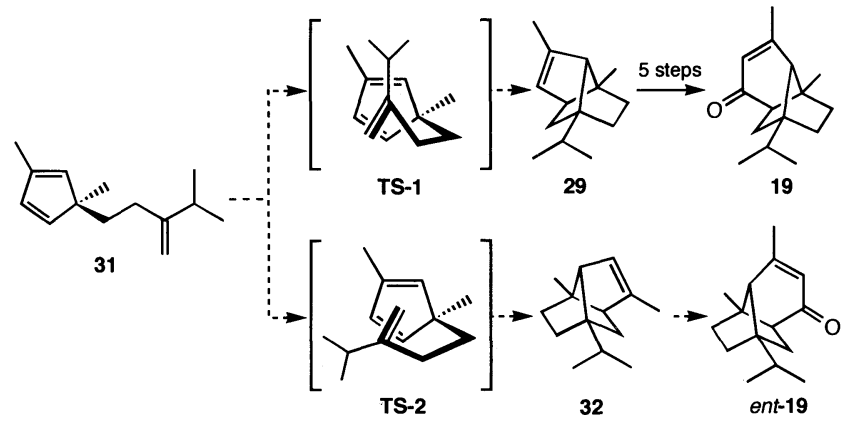

Fig. 7 Synthetic plan for both the enantiomers of 19.

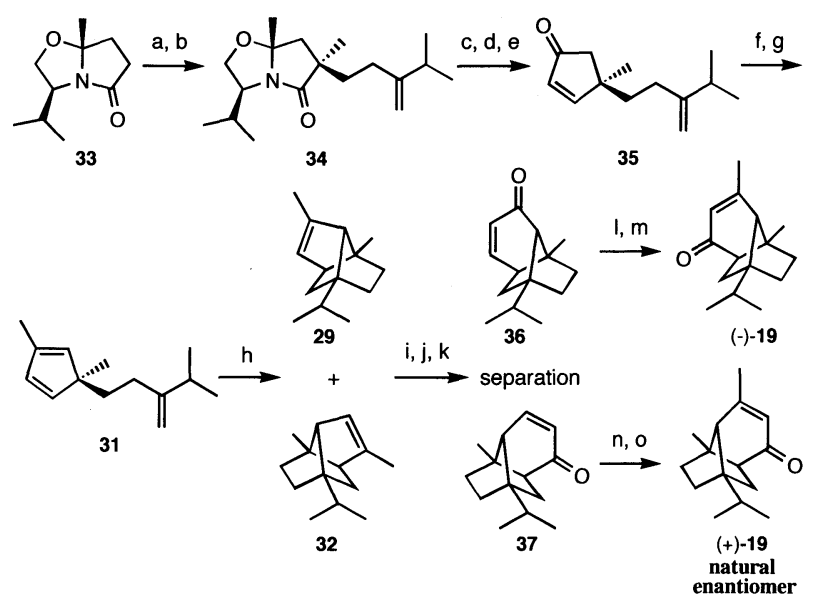

Fig. 8 Synthesis of both the enantiomers of the putative sex pheromone of $T$. marginata.

Reagents: a) s-BuLi, 4-iodo-2-isopropyl-1-butene, THFHMPA (74\%); b) s-BuLi, MeI, THF (89\%); c) Red-Al, THF; d) $(n-\mathrm{Bu})_{4} \mathrm{NH}_{2} \mathrm{PO}_{4}, \mathrm{H}_{2} \mathrm{O}-\mathrm{EtOH}$; e) $\mathrm{K}_{2} \mathrm{CO}_{3}, \mathrm{t}-\mathrm{BuOH}(45 \%, 5$ steps); f) LDA, $\mathrm{Tf}_{2} \mathrm{NPh}$, THF (80\%); g) $\mathrm{Me}_{2} \mathrm{CuLi}, \mathrm{THF}$ (86\%); h) $190{ }^{\circ} \mathrm{C}, 16 \mathrm{~h}$, methylene blue; i) $\mathrm{OsO}_{4}, \mathrm{Py}$, aq. $\mathrm{NaHSO}_{3}\left(78 \%, 2\right.$ steps); j) $\mathrm{NaIO}_{4}, \mathrm{H}_{2} \mathrm{O}$-ether (92\%); k) $\mathrm{K}_{2} \mathrm{CO}$ 3, $t$-BuOH (90\%: 36, 41\%; 37, 49\%); 1) MeLi, ether; m) PCC, $\mathrm{CH}_{2} \mathrm{Cl}_{2}\left(62 \%\right.$, 2 steps); n) $\mathrm{Me}_{2} \mathrm{CuLi}$, THF; o) $\mathrm{PhSeCl}$, EtOAc, then aq. $\mathrm{H}_{2} \mathrm{O}_{2}, \mathrm{NaHCO}_{3}$, THF (50\%, 2 steps).

全く進行しなかった。そこで, 27 をエノールトリフラート 経由で 29 とし ${ }^{21)}$ ，二重結合の酸化的開裂とアルドール縮合 により 30 とした後に, Dauben らの方法 ${ }^{22} に よ り( \pm)-19$ へ導いた。合成した $( \pm)-19$ の NMR，MS，GLC 保持時間 は天然物のものと完全に一致したことにより，Leal らによ り提案された構造の正しさを確認した。 $( \pm)-19$ の合成で は, 28 のシクロプロパン化が進行しないことがわかり， また 26a のエステル基をイソプロピル基に変換するため に 5 工程を要した。 そこで, 19 の光学活性体合成では 29 の 光学活性体を効率よく得る方法について考察した (Fig. 7). 29 は光学活性なトリエン 31 の遷移状態 TS-1 を経る分子 内 Diels-Alder 反応により調製可能であると考えられるが, この Diels-Alder 反応では 29 に至る遷移状態 (TS-1) の他
に TS-2のような遷移状態も可能であると考之られ，その 場合, 生成物は 32 となると予想される。注意深く両者を眺 めると, 29 と 32 とは構造異性体の関係にありながら, エナ ンチオメリックな関係に近いことが分かる.29は既にラセ ミ体合成経路によ19の光学活性体に導けることがわかっ ており，また32に対して適当な官能基変換を行之ば, 19 の 鏡像体（ent-19）に導けるものと考之た。即ち，31 の分子 内 Diels-Alder 反応により 29 と 32 とが混合物として得ら れ，それぞれを 19 および ent-19に導く過程で分離が可能 であれば，1.つの光学活性原料から 19 および ent-19の両 者が一度に得られることになる。この計画に従って，まず 31 の光学活性体の調製に着手した (Fig. 8). Meyers らの光 学活性シクロペンテノン合成法 ${ }^{23)}$ 適用して, レブリン酸 と $(S)$ - valinol から調製した光学活性ラクタム 33 に対し 2 回のアルキル化を行って 34 とし，さらに 3 工程で 35 を得 た. 35 をエノールトリフラート経由のメチル化によりトリ エン 30 に導いた後 ${ }^{24)}$, 分子内 Diels-Alder 反応の条件に付 したところ ${ }^{25)}, \mathbf{2 9}$ と $\mathbf{3 2}$ の混合物 $(\mathbf{2 9}: \mathbf{3 2}=45 ： 55)$ を与之 た。この時点では両者の分離はできなかったが，混合物の まま二重結合の酸化的開裂，アルドール縮合を行ったとこ ろ, TLC 上 2 スポットとなり, 通常のシリカゲルカラムで 36 および 37 を単離することができた. 36 はラセミ体合成 の時と同じ手法で(-)-19へ，また 37 は有機銅試薬の共役 付加とセレノキシドの脱離 ${ }^{26)}$ を経ることにより $(+)-19 に$ 導くことができた。両者の NMR は完全に一致し, 比旋光度 もよい対応を示した。こうして得られた両鏡像体をキラル な固定相を有するキャピラリーGLC 分析 (Chiralsil DEX $\mathrm{CB}, 25 \mathrm{~m} \times 0.25 \mathrm{~mm}$ ) に付したところ両者が分離可能である ことが判明した。そこで，保存されていた天然物も同じ条 件で分析してみたところ，天然物は $(+)-19$ に保持時間が 一致することが明らかとなり．天然物の絶対立体配置は (+)-19で表されることが確定した。合成品の生物活性に ついては今後，Leal らにより実施される予定である.

\section{おわりに}

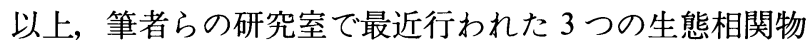
質の合成研究について紹介させていただいた。自然界には 生物間の相互作用に関わる興味深い機能と構造を持つ物質 がまだまだ数多く残されていると思われる，特に，これま での化学生態学は主に北半球中心に進められてきており, 南アメリカやオーストラリアなどには未解明の生態や， $T$. marginata の推定性フェロモンのように全く新規な構造を 有する化合物が眠っている可能性が指摘されている。 その ような生態の解明と農業生産技術改善への応用研究に, 有 機化学の立場から貢献していきたい. 


\section{引用 文 献}

1) 古前恒監修：化学生態学への招待, 三共出版, 1996

2) R. Baker, M. Borges, N. G. Cooke \& R. H. Herbert: J. Chem. Soc., Chem. Commun. 414 (1987)

3) J. R. Aldrich \& W. R. Lusby: Naturwissenschaften 76, 173 (1989)

4) J. R. Aldrich, J, E. Oliver, W. R. Lusby, J. P. Kochansky \& J. A. Lockwood: J. Exp. Zool. 244, 171 (1987)

5) B. E. Marron \& K. C. Nicolaou: Synthesis, 537 (1989)

6) H. Tomioka \& K. Mori: Biosci. Biotechnol. Biochem. 56, 1001 (1992)

7) L. H. B. Baptistella \& A. M. Aleixo: Liebigs Ann. Chem. 735 (1994)

8) T. Poll, A. Sobczak, H. Hartmen \& G. Helmchen: Tetrahedron Lett. 26, 3095 (1985)

9) A. Anciaux, A. Eman, W. Dumont \& A. Krief: Tetrahedron Lett. 1617 (1975)

10) J. N. Denis, W. Dumont \& A. Krief: Tetrahedron Lett. 4111 (1979)

11) S. Kuwahara, D. Itoh, W. S. Leal \& O. Kodama: Tetrahedron Lett. 39, 1183 (1998)

12) S. Kuwahara, D. Itoh, W. S. Leal \& O. Kodama: Tetrahedron 54, 11421 (1998)

13) H. T. Alborn, T. C. J. Turling, T. H. Jones, J. H. Loughrin \& J. H. Tumlinson: Science 276, 945 (1997)

14) P. W. Paŕ, H. T. Alborn \& J. H. Tumlinson: Proc. Natl. Acad. Sci. 13971 (1998)
15) C. M. De Moraes, W. J. Lewis, P. W. Paŕ H. T. Alborn \& J, H. Tumlinson: Nature 393, 570 (1998)

16) G. Pohnert, V. Jung, E. Hankioja, K. Lempa \& W. Boland: Tetrahedron 55, 11275 (1999)

17) A. Tanaka \& T. Oritani: Tetrahedron Lett. 38, 1955 (1997)

18) G. Pohnert, T. Koch \& W. Boland: Chem. Commun. 1087 (1999)

19) S. Takano, K. Inomata, K. Samizu, S. Tomita, M. Yanase, M. Suzuki, Y. Iwabuchi, T. Sugihara \& K. Ogasawara: Chem. Lett. 1283 (1989)

20) M. Ihara, K. Makita, Y. Fujiwara, Y. Tokunaga \& K. Fukumoto, J. Org. Chem. 61, 6416 (1996)

21) S. Cacchi, E. Morera \& G. Ortar: Tetrahedron lett. 25, 4821 (1984)

22) W. G. Dauben \& D. M. Michno: J. Org. Chem. 42, 682 (1977)

23) A. I. Meyers \& B. A. Lefker: Tetrahedron 43, 5663 (1987)

24) J. E. McMurry \& W. Scott: Tetrahedron Lett. 24, 979 (1983)

25) D. F. Taber \& S. A. Saleh: J. Am. Chem. Soc. 102, 5085 (1980)

26) K. B. Sharpless, R. F. Lauer \& A. Y. Teranishi: J. Am. Chem. Soc. 95, 6137 (1973) 